\title{
A Longitudinal Study Into Indicators of Mental Health, Strengths and Difficulties Reported by Boarding Students as They Transition From Primary School to Secondary Boarding Schools in Perth, Western Australia
}

\author{
David J. Mander ${ }^{1,2}$ and Leanne Lester ${ }^{1}$ \\ 1 Health Promotion Evaluation Unit, The University of Western Australia, Perth, Australia \\ 2 Edith Cowan University, Perth, Australia
}

\begin{abstract}
This study examined indicators of mental health, as well as strengths and difficulties, as reported by same-age boarding and non-boarding students spanning four time points over a 2-year period as they transitioned from primary to boarding school in Western Australia (i.e., at the end of Grade 7, beginning of Grade 8, end of Grade 8, and end of Grade 9). It presents data taken from a larger longitudinal quantitative study, which included 76 male and 74 female boarding students while they were in Grades 7 to 9 . Findings indicate that boarding students and non-boarding students reported significant increases in depression, anxiety, as well as emotional symptoms and hyperactivity over time, and reported significant decreases in prosocial behaviour. However, examining the boarder $x$ time interaction, boarding students reported significantly higher levels of anxiety and stress at the end of Grade 8 compared to non-boarding students. No significant difference over time was found in depressive symptomatology between boarding and non-boarding students, whereas at the beginning of Grade 8 and end of Grade 9, boarding students reported significantly higher emotional symptoms than non-boarding students. These findings are discussed in terms of the boarding school context and possible considerations for prevention and practice are presented.
\end{abstract}

Keywords: boarding schools, boarding students, mental health, strengths and difficulties, transition, Western Australia 


\section{Background}

The vast majority of boarding schools in Australia are non-government institutions that vary substantially in terms of overall number of boarding students, organisational structure and operational practices, as well as values and expectations, educational philosophy, and religious affiliation (Independent Schools Council of Australia [ISCA], 2016). The Australian Boarding Schools Association (ABSA) reported that 178 boarding schools exist across Australia in 2016, with 21,167 secondary boarding students in Years 4 to 12 attending these schools (ABSA, 2016). Of this total, 9,800 were female and 11,367 male, with 3,369 identifying as Indigenous and 2,004 as international boarding students. The largest subgroup of boarding students in 2016 was from rural locations, at 12,316 (ABSA, 2016). Yet, notwithstanding the efforts of Papworth (2014), evidence of longitudinal research exploring indicators of the emotional and mental impact of schooling away from home for boarding students in Australia, as well as the potential benefits, is surprisingly thin.

Despite this, many families living in rural areas of Australia continue to feel that boarding school is the only way to ensure their children receive a high-quality secondary education (Commonwealth of Australia, 2000; Isolated Children's Parents' Association [ICPA], n.d.). An Australian survey of 3,100 families with children at 68 boarding schools by Lawrence (2006), for example, found that although parents in rural locations were reluctant to send their children away to boarding school, $92 \%$ indicated they would still choose boarding if making the decision again. While scarce, Australian research has also outlined not only the highly complicated decision-making process for rural families when thinking about sending their children to boarding school, but equally provided evidence of a deep parental fear for their children's general safety, social and emotional wellbeing, and psychological needs, while they are away from the familiarity of home and security of family (Baker \& Andrews, 1991; Mander, 2015; A. McCarthy, 2007; M. McCarthy, 2016).

\section{Review of Studies Into the Mental Health and Wellbeing of Boarding Students in Australia}

Despite boarding schools being a longstanding a feature of the Australian education system, the scientific study of boarding students' emotional and mental health is not. Research by Fisher, Elder, and Peacock (1990) investigated homesickness in 112 students at a single coeducational boarding school in Victoria. They found that by week 6 of the first term, new boarding students were unhappier than boarding students who had previously experienced schooling away from home, and reported that some new boarding students exhibited symptoms they associated with anxiousness and depression. Mason (1997) investigated the transition experience for 38 new Grade 8 students at a boarding hostel in Western Australia (WA). Positive self-esteem and confidence combined with the ability to adapt to change was reportedly linked with less emotional distress during the transition experience. However, Mason (1997) also reported that those students who found the transition difficult displayed emotional problems and were often easily upset, and became aggressive, withdrawn, or heavily dependent on others to cope in the boarding hostel. 
Longitudinal research by Downs $(2001,2003)$ similarly investigated how students coped with the transition experience at two single-sex boarding schools in North Queensland. Following 74 new Grade 8 students (35 boarding students, 39 non-boarding students) over a 10-month period, Downs (2001, 2003) surveyed them at the beginning of Term 1 and Term 4. No significant difference was found in symptomatology associated with depression during Term 1 between male and female or boarding and non-boarding students. Rather, the majority of students reported their transition to a boarding school was a positive experience. No marked change in emotional stability (e.g., moodiness, worry, and feeling upset) was identified throughout the first part of the year for boarding students; however, Downs did describe how by Term 4, female boarding students reported feeling more depressed than males (Downs, 2001, 2003).

A mixed-method, cross-sectional study by Bramston and Patrick (2007) used both focus groups and a survey to investigate the transition experience for 36 new boarding students in Grades 6 to 11 at six boarding schools in Queensland. They reported that $60 \%$ of these students experienced homesickness but that none of these students perceived it as a serious issue. When compared with new non-boarding students of the same age, Bramston and Patrick (2007) found no significant difference in symptomatology-associated anxiousness or depression, or in levels of psychological distress. Rather, like Downs (2001), students reported boarding school was a positive experience, and their primary concern was adjusting to new academic expectations (Bramston \& Patrick, 2007).

A mixed-method, cross-sectional study by Whyte and Boylan (2008) similarly surveyed 89 boarding students aged 12 to 14 years (44 male, 45 female) at three coeducational boarding schools in New South Wales and southern Queensland. Like Bramston and Patrick (2007), they reported that $64 \%$ of new boarding students reported experiencing homesickness; however, no difference was found in emotional stability between boarding and non-boarding students. Yet, similar to Hodges, Sheffield, and Ralph (2013), they did conclude, 'all members of boarding school staff need to be aware of the issues that rural year seven students face upon entering the boarding school environment' (Whyte \& Boylan, 2008, p. 16).

Martin, Papworth, Ginns, and Liem (2014) conducted a longitudinal study into the academic motivation, engagement, and psychological wellbeing of 2,002 students at 12 Australian boarding schools in Grades 6 to 12 (28\% boarding students; $72 \%$ non-boarding students). They found that new boarding students initially reported higher scores in maladaptive motivation and emotional instability, and lower scores in peer relations, when compared with new non-boarding students. However, over the course of the first academic year, few significant gains or declines in engagement, motivation, and psychological wellbeing were found for boarding students, or between boarding and non-boarding students. Rather, like Downs (2001) and Bramston and Patrick (2007), boarding students were reported to experience significant positive growth in life satisfaction, sense of meaning and purpose, as well as in child-parent relations when compared with non-boarding students (Martin et al., 2014).

Each of these studies make an important contribution; however, it is remarkable that much of the existing research is limited to investigations of boarding students' mental health, strengths and difficulties once they have arrived at boarding school. 
In contrast, Mander, Lester, and Cross (2015) surveyed 3,462 primary school students from 21 schools, which included 76 male and 74 female Year 7 students before they transitioned to a boarding school. No difference was found between boarding and non-boarding students with regard to mental health, strengths and difficulties (Mander et al., 2015). However, after taking into account gender, baseline social and emotional indicators, and mental health at the beginning of Grade 8 , they found these new boarding students reported greater emotional symptoms, as well as greater levels of indicators associated with depression, anxiety and stress when compared with non-boarding students. It is interesting that at the beginning of Grade 8, no difference was found between boarding and non-boarding students in terms of social wellbeing; rather, emotional symptoms and mental health indicators seemed to mediate new boarding students' self-reported transition experience (Mander et al., 2015).

\section{The Present Study}

This study examined whether differences existed between indicators of mental health, as well as between strengths and difficulties, for same-age non-boarding and boarding students spanning four time points over a 2-year time period (i.e., at the end of Grade 7, then post-transition to boarding school at the beginning of Grade 8, as well as at the end of Grade 8 and end of Grade 9). It was hypothesised that boarding students may initially report poorer mental health than non-boarding students immediately after transition, but these effects would ameliorate by the end of Grade 8.

\section{Method}

This study used data taken from a larger longitudinal study, the Supportive Schools Project (SSP) conducted in Perth, Western Australia. Only data from the study comparison schools are used in this analysis, as the intervention is not a focus of this article. Approval to conduct this study was provided by the Edith Cowan University Human Research Ethics Committee and the Catholic Education Office of Western Australia (CEOWA).

\section{Participants and Data Collection}

Secondary schools affiliated with the CEOWA were recruited to participate in the study. Active consent was requested from all parents. For those parents who did not respond to this active consent approach, up to two follow-up letters were mailed to them requesting their passive consent where they were required to opt out if they did not wish their child to participate (Ellickson \& Hawes, 1989). This twolayered active then passive consent process resulted in $93 \%$ of parents consenting to their child participating in the study. Intervention and comparison cohort data were collected from students at 21 schools, of which four were boarding schools.

The data used in this research were collected from 3,459 students in four waves. Students completed a baseline questionnaire in Term 4 of the final year of primary school (Grade 7, average age 12 years) and then follow-up questionnaires at the beginning and the end of the first year after transition to secondary school (Grade 8 , average age 13 years) and 12 months later (i.e., at the end of Grade 9). In 
total, $90 \%$ of the total students recruited identified as non-boarding and $89 \%$ of boarding students completed questionnaires for at least three of the four data collection points. One half of the students surveyed were male, and $70 \%$ attended a coeducational secondary school versus a single-sex secondary school. An overall total of $5 \%$ of students (76 males, 74 females) in the SSP identified themselves as temporarily living away from home (e.g., as a boarding student) to complete their secondary education.

\section{Measures}

Strengths and Difficulties Questionnaire. The Strengths and Difficulties Questionnaire (SDQ) is a 25-item screening tool appropriate for use with 4- to 17-year-olds (Goodman, 1997) and uses a 3 -point scale $(0=$ not true, $1=$ somewhat true, $2=$ certainly true). The SDQ measures strengths (10 items) and difficulties (15 items) over the last month and comprises five subscales (emotional symptoms, conduct problems, hyperactivity, peer problems, prosocial behaviour), and an overall total difficulties score can be calculated. The conduct problems (average alpha $=0.37$ ) and peer problems (average alpha $=0.51$ ) subscales were excluded as they have low psychometric properties and could undermine any interpretations, conclusions, and implications drawn by this study. Subsequently, this also meant that no overall total difficulties score was able to be calculated either. An emotional symptoms (average alpha $=0.70$ ), hyperactivity (average alpha $=0.65$ ), and prosocial score (average alpha $=0.68$ ) was calculated at each time point for each student (e.g., a higher score for the prosocial subscale indicates strong social skills). These subscales were categorised into close to average (and unlikely to be clinically significant), slightly raised (may reflect clinically significant problems), and a high substantial risk of clinically significant problems.

Depression Anxiety Stress Scales-21. The Depression Anxiety Stress Scales-21 (DASS-21) is a 21-item, self-report inventory designed to screen, identify, differentiate, and assess three negative affective states, including depression, anxiety, and stress (Lovibond \& Lovibond, 1995). It is designed for individuals 12 years and older and is commonly used with youth and young people (Sethi, 2012; Venning, Wilson, Kettler, \& Eliott, 2013). It is composed of three subscales comprising seven items related to depression, anxiety, and stress. The DASS-21 uses a 4-point Likert scale from 0 (did not apply to me at all) to 3 (applied to me very much or most of the time) to indicate the extent to which an individual has experienced each affective state during the past week (Lovibond \& Lovibond, 1995). A depression (average alpha $=0.90)$, anxiety (average alpha $=0.85)$, and stress (average alpha $=0.87$ ) score was calculated at each time point for each student. Higher scores reflect greater levels of distress. The DASS-21 has been shown to be reliable with diverse adolescent populations (Mellor et al., 2015).

\section{Data Analysis}

Separate mixed regression models were fitted in STATA v13 and were used to determine whether indicators of mental health indicators (DASS-21) and strengths and difficulties $(\mathrm{SDQ})$, measured at four times points, differed by boarding and non-boarding status over time. A three-level, mixed regression model, taking into 
account gender and school type, was fitted to the data to account for the repeated observations of prosocial, hyperactivity, emotional symptoms, and mental health (level 1), nested within students (level 2), who in turn are clustered within schools (level 3). Chi-square analysis was used to determine differences in DASS-21 and SDQ severity categories between boarders and non-boarders.

\section{Results}

\section{Descriptive Statistics}

A summary of participant descriptive statistics is shown in Table 1, with the means and standard deviations for mental health, strengths and difficulty variables reported by boarding and non-boarding status at four time points. The majority of boarding and non-boarding students reported scores associated with average strengths and difficulties, and reported scores associated with normal to moderate symptoms of depression, anxiety, and stress.

A longitudinal analysis of boarders $(n=78)$ and non-boarders $(n=1,636)$ who were present at all four time points was conducted to determine whether differences existed between the two groups with respect to SDQ and DASS scores. When categorising the SDQ into average, slightly raised, and high substantial risk of clinically significant problems, non-boarders had a significantly greater proportion of students in the average category for prosocial behaviour at the end of Grade $8(88 \%$ to $80 \%$ respectively, $\left.\chi^{2}=26.385, p<.001\right)$. There were no significant differences between SDQ categories for boarders and non-boarders with respect to emotional symptoms and hyperactivity. When categorising the DASS-21 to represent the degree of severity relative to population norms, non-boarders had a significantly greater proportion of students in the normal category than boarders for symptoms associated with depression (beginning of Grade 8: $84 \%$ to $76 \%$ respectively, $\chi^{2}=$ $12.975, p=.011$; end of Grade $8: 84 \%$ to $73 \%$ respectively, $\chi^{2}=13.133, p=$ .011 ), anxiety (end of Grade $8: 86 \%$ to $72 \%$ respectively, $\chi^{2}=17.670, p<.001$ ), and stress (end of Grade 8: $91 \%$ to $80 \%$ respectively, $\chi^{2}=13.103, p=.011$ ) after transition into secondary school.

Separate multilevel models were used to examine the significance of change over time for mental health and indicators of strengths and difficulties for boarding and non-boarding students. Subscales of the DASS-21 (depression, anxiety, and stress) and the SDQ (emotional symptoms, hyperactivity, and prosocial) were explored as outcomes of boarder status at each of the four time points. Both boarders and non-boarders reported significant increases in depression, anxiety, as well as emotional symptoms and hyperactivity over time (all $p<.01)$ and reported significant decreases in prosocial behaviour (all $p<.05$ ).

However, examining the boarder $\times$ time interaction, boarding students reported significantly higher levels of anxiety $(p=.009)$ and stress $(p=.045)$ at the end of Grade 8 compared to non-boarding students (Table 2). No significant difference over time was found in depressive symptomatology between boarding and nonboarding students (all $p<.05)$, whereas at the beginning of Grade $8(p=.042)$ and end of Grade 9, boarding students reported significantly higher emotional symptoms $(p=.039)$ than non-boarding students 


\section{TABLE 1}

Descriptive Statistics of Mental Health, Strength and Difficulty Factors and Boarder Status

\begin{tabular}{|c|c|c|c|c|c|c|c|c|}
\hline \multirow[b]{2}{*}{ Mean (SD) } & \multicolumn{2}{|c|}{ End of Grade 7} & \multicolumn{2}{|c|}{ Beginning of Grade 8} & \multicolumn{2}{|c|}{ End of Grade 8} & \multicolumn{2}{|c|}{ End of Grade 9} \\
\hline & $\begin{array}{l}\text { Boarder } \\
(n=89)\end{array}$ & $\begin{array}{l}\text { Non-boarder } \\
(n=1,786)\end{array}$ & $\begin{array}{l}\text { Boarder } \\
(n=148)\end{array}$ & $\begin{array}{l}\text { Non-boarder } \\
(n=2,913)\end{array}$ & $\begin{array}{l}\text { Boarder } \\
(n=150)\end{array}$ & $\begin{array}{l}\text { Non-boarder } \\
(n=2,952)\end{array}$ & $\begin{array}{l}\text { Boarder } \\
(n=131)\end{array}$ & $\begin{array}{l}\text { Non-boarder } \\
(n=2,698)\end{array}$ \\
\hline \multicolumn{9}{|l|}{ Mental health (DASS) } \\
\hline Depression & $4.68(7.78)$ & $3.80(6.20)$ & $7.54(10.09)$ & $4.92(7.98)$ & $7.57(11.43)$ & $4.85(8.28)$ & $7.29(10.83)$ & $5.85(9.37)$ \\
\hline Anxiety & $3.69(6.43)$ & $3.35(5.15)$ & $6.59(8.42)$ & $4.45(6.91)$ & $6.67(10.58)$ & $3.85(6.83)$ & $6.04(10.17)$ & $4.54(7.78)$ \\
\hline Stress & $6.92(8.64)$ & $6.15(6.81)$ & $8.18(8.79)$ & $6.15(7.87)$ & $8.27(10.95)$ & $5.51(7.88)$ & $7.67(10.76)$ & $6.66(8.88)$ \\
\hline \multicolumn{9}{|c|}{ Emotional wellbeing (SDQ) } \\
\hline Emotional symptoms & $2.18(2.04)$ & $2.11(2.10)$ & $2.78(2.46)$ & $2.28(2.30)$ & $2.73(2.57)$ & $2.32(2.37)$ & $3.02(2.57)$ & $2.52(2.43)$ \\
\hline Hyperactivity & $3.55(2.07)$ & $2.98(2.20)$ & $3.73(2.31)$ & $3.26(2.32)$ & $4.05(2.43)$ & $3.37(2.43)$ & $4.05(2.21)$ & $3.75(2.48)$ \\
\hline Prosocial behaviour & $8.28(1.54)$ & $8.40(1.57)$ & $7.84(1.90)$ & $7.86(1.83)$ & $7.30(2.52)$ & $7.79(1.91)$ & $7.21(2.44)$ & $7.56(2.13)$ \\
\hline
\end{tabular}


TABLE 2

Multi-Level Modelling Results of Mental Health, Strengths and Difficulties, Adjusted for Boarder Status, Time, and Boarder Status $\times$ Time

\begin{tabular}{|c|c|c|c|c|c|c|}
\hline All students & Depression (SE) & Anxiety (SE) & Stress (SE) & $\begin{array}{l}\text { Emotional } \\
\text { symptoms (SE) }\end{array}$ & Hyperactivity (SE) & $\begin{array}{l}\text { Prosocial } \\
\text { behaviour (SE) }\end{array}$ \\
\hline \multicolumn{7}{|l|}{ Fixed parameters } \\
\hline Intercept & $3.94(0.43)^{* *}$ & $3.69(0.35)^{* *}$ & $6.47(0.41)^{* *}$ & $2.54(0.12)^{* *}$ & $2.65(0.13)^{* *}$ & $8.98(0.10)^{* *}$ \\
\hline Gender & $-0.20(0.26)$ & $0.02(0.22)$ & $-0.15(0.26)$ & $-0.67(0.08)$ & $0.34(0.08)^{* *}$ & $-0.97(0.06)^{* *}$ \\
\hline \multicolumn{7}{|l|}{ School type } \\
\hline Co-educational & $0.26(0.35)$ & $-0.13(0.28)$ & $-0.02(0.34)$ & $0.07(0.11)$ & $0.43(0.11)^{* *}$ & $0.16(0.08)^{* *}$ \\
\hline Female only & $-0.26(0.51)$ & $-1.01(0.41)^{*}$ & $-0.57(0.49)$ & $-0.32(0.15)$ & $-0.01(0.16)$ & $-0.33(0.11)$ \\
\hline Boarder & $1.32(0.87)$ & $1.04(0.74)$ & $1.09(0.85)$ & $0.14(0.23)$ & $0.73(0.24)^{* *}$ & $-0.29(0.19)$ \\
\hline \multicolumn{7}{|l|}{ Time } \\
\hline Post 1: Start of Grade 8 & $0.83(0.20)^{* *}$ & $0.89(0.18)^{* *}$ & $-0.23(0.20)$ & $0.07(0.05)$ & $0.14(0.05)^{* *}$ & $-0.42(0.04)^{* *}$ \\
\hline Post 2: End of Grade 8 & $0.71(0.20)^{* *}$ & $0.23(0.18)$ & $-0.92(0.20)^{* *}$ & $0.11(0.05)^{*}$ & $0.23(0.05)^{* *}$ & $-0.50(0.04)^{* *}$ \\
\hline Post 3: End of Grade 9 & $1.88(0.21)^{* *}$ & $1.06(0.18)^{* *}$ & $0.37(0.20)$ & $0.35(0.05)^{* *}$ & $0.65(0.05)^{* *}$ & $-0.76(0.04)^{* *}$ \\
\hline \multicolumn{7}{|l|}{ Boarder $\times$ Time } \\
\hline Boarder $\times$ Post 1 & $1.37(0.93)$ & $1.45(0.81)$ & $1.17(0.92)$ & $0.48(0.24)^{*}$ & $-0.11(0.22)$ & $0.14(0.20)$ \\
\hline Boarder $\times$ Post 2 & $1.70(0.93)$ & $2.10(0.81)^{* *}$ & $1.82(0.91)^{*}$ & $0.34(0.24)$ & $0.04(0.22)$ & $-0.38(0.20)$ \\
\hline Boarder $\times$ Post 3 & $0.58(0.95)$ & $0.92(0.83)$ & $0.37(0.94)$ & $0.50(0.24)^{*}$ & $-0.22(0.23)$ & $-0.24(0.21)$ \\
\hline \multicolumn{7}{|l|}{ Random parameters } \\
\hline Level 3 (school variance) & $0.12(0.02)$ & $0.11(0.01)$ & $0.09(0.02)$ & $0.01(0.02)$ & $0.01(0.02)$ & $0.01(0.01)$ \\
\hline Level 2 (between student variance) & $4.58(0.21)$ & $3.45(0.19)$ & $4.58(0.21)$ & $1.62(0.03)$ & $1.77(0.09)$ & $1.18(0.02)$ \\
\hline Level 1 (within student variance) & $6.44(0.05)$ & $5.63(0.05)$ & $6.35(0.05)$ & $1.65(0.01)$ & $1.56(0.01)$ & $1.41(0.01)$ \\
\hline
\end{tabular}

Note: $S E=$ standard error. Reference categories: Gender - female, School type - male only, Boarder — not boarder; Time — Baseline end of Grade 7 . ${ }^{*} p<.05,{ }^{* *} p<.01$. 


\section{Discussion}

This study examined indicators of mental health, as well as strengths and difficulties, reported by same-age boarding and non-boarding students spanning four time points over a 2-year period as they transitioned from primary to boarding school in WA (i.e., at the end of Grade 7, beginning of Grade 8, end of Grade 8, and end of Grade 9). The main findings indicate that while both boarding and non-boarding students reported significant decreases in prosocial behaviour, boarding students reported significantly greater emotional symptoms and mental health indicators when compared with non-boarders. Building on from previous research (Mander et al., 2015), the findings of this study suggest that both the immediate and the long-term emotional symptoms and mental health of boarding students during and post the primary to boarding school transition warrants further consideration in general.

Teachers and boarding staff play a crucial role in ensuring new boarding students successfully adjust to life at a new boarding school (Hawkes, 2010a, 2010b). However, Hodges et al.'s (2013) recent assertion that staff in Australian boarding schools would benefit from further training in developmental changes during adolescence appears to have merit. Indeed, the current research suggests targeted education about indicators of emotional wellbeing and mental health during early adolescence would enable staff in boarding schools to better identify and make informed decisions about the overall health and wellbeing of boarding students. Research has shown, for example, that teachers provide accurate assessments of the impact problems at school can have on a student's immediate and future educational attainment (Coleman et al., 2009).

It is beyond the scope of this study to provide an exhaustive summary of features associated with the promotion of positive wellbeing and preventative mental health approaches in schools. However, there are some common features shared by those schools that do it better than others (Lester \& Cross, 2015; Waters, Lester, \& Cross, 2014). School environments that foster stable, high-quality teacher-student relationships have been associated with lower levels of student emotional difficulties (Hattie, 2009, 2012; Miller-Lewis et al., 2014). Similarly, although a suite of schoolbased social and emotional programs now exist in various forms (e.g., universal, selective, indicated, and multi-component), those schools that commit the time and resources to rigorously evaluate the robustness of evidence underpinning these programs (e.g., independently and systematically evaluated via randomised control trials), seem to implement programs, practices, and policies that better meet the unique needs of their student population and school environment (Bywater \& Sharples, 2012).

It is important to acknowledge that experiencing moderate states of anxiety and stress during the transition to secondary school is, for the most part, normal (Akos, Queen, \& Lineberry, 2005). Some suggest this transition forms a rite of passage and is an important part of developing coping strategies and adaptive responses to change in life, as well as contributes to strengthening the resourcefulness, motivation, and resilience of young people (Benner, 2011). Research has shown, for example, that exposure to moderate states of anxiety and/or stress that young people perceive as temporary and as having some control over attain on average higher 
academic outcomes (Morin, 2011) and have a lower risk of school dropout (Borges, Mendina Mora-Icaza, Benjet, Lee, \& Breslau, 2011). However, prolonged exposure to experiences young people perceive as aversive, threatening, and uncontrollable are equally associated with evoking a heightened state of distress, poor sleeping patterns, school refusal, lower academic attainment, and diminished motivation (Barrett, 2014; Esch et al., 2014).

The present study suggests that over time, boarding students had a significantly less proportion of students compared with non-boarding students within the normal ranges for symptoms associated with depression, anxiety, and stress after the transition to boarding school. It would seem beneficial for boarding schools to reflect on orientation processes and how they prepare for and support new boarding students to negotiate the impending transition experience (Coffey, Berlach, \& O'Neil, 2011; Waters et al., 2014). Similarly, given the significance of parents and family functioning during childhood to the promotion of positive mental health in adolescence (Renzaho, Mellor, McCabe, \& Powell, 2013), an important adjunct would be for boarding schools to examine ways in which they can maximise parental engagement; in particular, ways in which they can support parents to prepare their children during the years prior to the impending transition to boarding school and reduce the likelihood of an abrupt disjuncture when it happens. Strong empirical support exists, for example, for the efficacy and effectiveness of positive parenting programs such as Triple P (Dadds, 2012; Sanders \& Kirby, 2014). One potential direction is to consider how this or similar child-centred parenting and family support systems can be adapted for and made accessible to rural families, as well as to help rural parents prepare for possible difficulties with adjustment to a new boarding environment for their children.

\section{Future Research}

No mental health prevention programs specifically address the various ecological layers in boarding school environments. MindMatters, for example, offers secondary schools a framework consisting of four components designed to help them understand and improve the mental health and wellbeing of young people. It blends professional learning with interactive activities that can be structured relative to diverse school contexts. It also provides examples of school-wide prevention strategies, parent activities, staff training, and classroom-focused lessons in an effort to promote a holistic and positive school culture. That said, further independent research into MindMatters is still needed, and it will be important for individual boarding schools to discern how MindMatters can best meet the unique needs of their school community, while being vigilant for any possible iatrogenic effects.

\section{Strengths and Limitations}

The current study highlights the importance for future research to investigate symptoms associated with anxiety and depression separately for adolescent populations in boarding school contexts. Depression during adolescence is often comorbid with anxiety disorders, as well as with childhood behavioural disorders and oppositional problems (Rutter, 2007). Yet, little research has investigated the influence of anxious disorders such as social anxiety disorder, separation anxiety disorder, panic 
attacks, social phobias, and generalised anxiety disorder, as separate from other affective disorders during significant transition periods for students and in boarding school contexts (Borges et al., 2011; Riglin, Petrides, Frederickson, \& Rice, 2014). Similarly, it would be important for these future studies to disentangle the direction of effect for affective disorders and better understand potential moderators (Papworth, 2014; Martin et al., 2014).

This study has the following limitations. The low Cronbach alphas for both conduct and peer problems possibly suggest a need to review the SDQ. It is not only important to review how emotional symptoms are measured but also determine whether the DASS-21 requires further modification to be useful with adolescent (Shaw, Campbell, Runions, \& Zubrick, 2016; Szabo, 2010) and boarding school populations. Given the sample size, the current findings should be interpreted with caution. They should be considered as support for a longitudinal, randomised control trial, with more power to capture how boarding students internalise and externalise problems experienced during the transition experience to boarding school. The findings here suggest further research is needed to better discern the empirical relations between social competence, emotional wellbeing, and mental health issues for the boarding students.

In sum, the data from this longitudinal study provided preliminary support for further targeted research to better understand early indicators of emotional symptoms and mental health factors that are associated with boarding students as they transition from a local primary schools to secondary boarding school way from home. A better understanding of these factors may help rural parents prepare their children and boarding schools to identify opportunities to develop and implement preventative policy and practices.

\section{References}

Akos, P., Queen, A.J., \& Lineberry, C. (2005). Promoting a successful transition to middle school. New York: Eye on Education.

Australian Boarding Schools Association. (2016). Census 2016. Brisbane, Australia: Author.

Baker, R., \& Andrews, J. (1991). Parental reasons for sending children to a rural day and boarding school. Education in Rural Australia, 1, 21-26.

Barrett, P. (2014). Childhood anxiety disorders. InPsych, 36, 15.

Benner, A.D. (2011). The transition to high school: Current knowledge, future directions. Educational Psychology Review, 23, 299-328. doi:10.1007/s10648011-9152-0

Borges, G., Mendina Mora-Icaza, M.E., Benjet, C., Lee, M., \& Breslau, J. (2011). Influence of mental health disorders on school dropout in Mexico. Pan American Journal of Public Health, 30, 477-483.

Bramston, P., \& Patrick, J. (2007). Rural adolescents experiencing an urban transition. Australian Journal of Rural Health, 15, 247-251. doi:10.1111/j.14401584.2007.00897.x

Bywater, T., \& Sharples, J. (2012). Effective evidence-based interventions for emotional well-being: Lessons for policy and practice. Research Papers in Education, 27, 389408. doi:10.1080/02671522.2012.690242 
Coffey, A., Berlach, R.G., \& O’Neill, M. (2011). Transitioning year seven primary students to secondary settings in Western Australian Catholic schools: A description of the process. Journal of Catholic School Studies, 83, 7-17.

Coleman, I., Murray, J., Abbott, A.A., Maughan, B., Kuh, D., Croudance, T.J., \& Jones, P.B. (2009). Outcomes of conduct problems in adolescence: 40 year followup of national cohort. British Medical Journal, 338. doi:https://doi.org/10.1136/bmj. a2981

Commonwealth of Australia. (2000). Education access: National inquiry into rural and remote education. Canberra, Australia: Human Rights and Equal Opportunities Commission. Retrieved from https://www.humanrights.gov.au/our-work/rightsand-freedoms/projects/rural-and-remote-education-inquiry

Dadds, M. (2012). Helping troubled children: Seven things you should know about the origins of mental health disorders. InPsych, 34, 8-11.

Downs, J. (2001). Coping with change: Adolescents' experiences of transition to secondary and boarding school (Doctoral dissertation). Retrieved from http://trove.nla. gov.au/work/35503242

Downs, J. (2003, November). Self-concept during the transition to secondary school: Turmoil or normative adjustment? Paper presented at the NZARE AARE, Auckland, New Zealand. Retrieved from http://www.aare.edu.au/03pap/dow03790. pdf

Ellickson, P., \& Hawes, J. (1989). An assessment of active versus passive methods for obtaining parental consent. Evaluation Review, 13, 45-55. doi:10.1177/ 0193841X8901300104

Esch, P., Bocquet, V., Pull, C., Couffignal, S., Lehnert, T., Graas, M., Fond-Harmant, L., \& Ansseau, M. (2014). The downward spiral of mental disorders and educational attainment: A systematic review on early school leaving. BMC Psychiatry, 14, 237. doi:10.1186/s12888-014-0237-4

Fisher, S., Elder, L., \& Peacock, G. (1990). Homesickness in a school in the Australian bush. Children's Environments Quarterly, 7, 15-22.

Goodman, R. (1997). The Strengths and Difficulties Questionnaire: A research note. Journal of Child Psychology \& Psychiatry, 38, 581-586. doi:10.1111/j.14697610.1997.tb01545

Hattie, J. (2009). Visible learning: A synthesis of over 800 meta-analyses relating to achievement. Milton Park, UK: Routledge.

Hattie, J. (2012). Visible learning for teachers: Maximizing impact on learning. Milton Park, UK: Routledge.

Hawkes, T. (2010a). Duty of care: A certificate course in residential care - Book one. Sydney, Australia: The King's School.

Hawkes, T. (2010b). Duty of care: A certificate course in residential care - Book two. Sydney, Australia: The King's School.

Hodges, J., Sheffield, J., \& Ralph, A. (2013). Home away from home? Boarding in Australian schools. Australian Journal of Education, 57, 32-47. doi:10.1177/ 0004944112472789

Independent Schools Council of Australia (ISCA). (2016). Snap shot 2016. Canberra, Australia: Author. Retrieved from http://isca.edu.au/wp-content/uploads/2011/ 03/ISCA-Snapshot-2016-A4-2pp.pdf

Isolated Children's Parents' Association (ICPA). (n.d.). Retrieved from http://www. icpa.com.au 
Lawrence, R. (2006). The sustainability of boarding: Choice and influencing factors of parents who elect to send their children to boarding school. Melbourne, Australia: Prospect Research and Marketing.

Lester, L, \& Cross, D. (2015). The relationship between school climate and mental and emotional wellbeing over the transition from primary to secondary school. Psychology of Well-Being: Theory, Research and Practice, 5, 1-15. doi:10.1186/s13612-015-0037-8

Lovibond, S.H., \& Lovibond, P.F. (1995). The structure of negative motional states: Comparison of the Depression Anxiety Stress Scales (DASS) with the Beck Depression and Anxiety Inventories. Behavior Research and Therapy, 33, 334-335. doi:10.1016/0005-7967(97)00075-U

Mander, D.J. (2015). Enabling voice: Aboriginal parents, experiences and perceptions of sending a child to boarding school in Western Australia. Australian Journal of Indigenous Education, 44, 173-183. doi:https://doi.org/10.1017/jie.2015.21

Mander, D.J., Lester, L., \& Cross, D. (2015). The social and emotional well-being, and mental health implications for adolescents transitioning to secondary boarding school. International Journal of Child and Adolescent Health, 8, 131-140.

Martin, A.J., Papworth, B., Ginns, P., \& Liem, G.A.D. (2014). Boarding school, academic motivation and engagement, and psychological well-being: A large scale investigation. American Journal of Educational Research, 51, 1007-1049. doi:10.3102/0002831214532164

Mason, K. (1997, July). The emotional transition of twelve year olds from home to a boarding situation. Paper presented at the National Conference of the Society for the Provision of Education in Rural Australia (SPERA), Adelaide, South Australia. Retrieved from http://eric.ed.gov/?id=ED429797

McCarthy, A. (2007). Managing school choice. Issues in Educational Research, 17, 232-255.

McCarthy, M. (2016). Parental choices of school by rural and remote parents. Issues in Educational Research, 26, 29-44. doi: www.iier.org.au/iier26/mccarthy.pdf

Mellor, D., Vinet, E.V., Xu, X., Hidayah Bt Mamat, N., Richardson, B., \& Roman, F. (2015). Factorial invariance of the DASS-21 among adolescents in four countries. European Journal of Psychological Assessment, 31, 138-142. doi:10.1027/1015-5759/a000218

Miller-Lewis, L., Sawyer, A.C. P., Searle, A.K., Mittinty, M.N., Sawyer, M.G., \& Lynch, J.W. (2014). Student-teacher relationship trajectories and mental health problems in young children. BMC Psychology, 2, 2-18. Retrieved from http://biomedcentral.com/2050-7283/2/27

Morin, A.J.S. (2011). General growth mixture analysis of adolescents' developmental trajectories of anxiety: The impact of untested invariance assumptions on substantive interpretations. Structural Equation Modeling, 18, 613-648. doi: 10.1080/10705511.2011.607714

Papworth, B.A. (2014). Attending boarding school: A longitudinal study of its role in students' academic and non-academic outcomes (Unpublished doctoral thesis), University of Sydney, Australia.

Renzaho, A., Mellor, D., McCabe, M., \& Powell, M. (2013). Family functioning, parental psychological distress and child behaviours: Evidence from the Victorian Child Health Well-being Study. Australian Psychologist, 48, 217-225. doi:10.1111/j.1742-9544.2011.00059.x 
Riglin, L., Petrides, K.V., Frederickson, N., \& Rice, F. (2014). The relationship between emotional problems and subsequent school attainment: A meta-analysis. Journal of Adolescence, 37, 335-346. doi:10.1016/j.adolescence.2014.02.010

Rutter, M. (2007). Psychopathological development across adolescence. Journal of Youth Adolescence, 36, 101-110. doi:10.1007/s10964-006-9125-7

Sanders, M., \& Kirby, J. (2014). Childhood behavioural disorders. InPsych, 36, 14.

Sethi, S. (2012). Treating youth depression and anxiety: A randomised controlled trail examining the efficacy of computerised verses face-to-face cognitive behaviour therapy. Australian Psychologist, 48, 249-257. doi:10.1111/ap.12006

Shaw, T., Campbell, M.A., Runions, K.C., \& Zubrick, S.R. (2016). Properties of the DASS-21 in an Australian community adolescent population: Applicability of the DASS-21 to adolescents. Journal of Clinical Psychology, 10. doi:https://doi.org/10.1002/jclp.22376

Szabo, M. (2010). The short version of the Depression Anxiety Stress Scales (DASS21): Factor structure in a young adolescent sample. Journal of Adolescence, 33, 1-8. doi:10.1016/j.adolescence.2009.05.014

Venning, A., Wilson, A., Kettler, L., \& Eliott, J. (2013). Mental health among youth in South Australia: A survey of flourishing, languishing, struggling, and floundering. Australian Psychologist, 48, 299-310. doi: 10.1111/j.1742-9544.201200068.x

Waters, S.K., Lester, L., \& Cross (2014). Transition to secondary school: Expectation versus experience. Australian Journal of Education, 58(2), 153-166. doi:10.1177/0004944114523371

Whyte, M., \& Boylan, C. (2008, November-December). Rural primary student transition to secondary boarding school. Paper presented at the AARE 2008 International Education Research Conference (Paper Code: BOY08069), Brisbane, Australia. 